\title{
RELEVANSI HAK KEKAYAAN INTELEKTUAL DENGAN HAK ASASI MANUSIA GENERASI KEDUA
}

\author{
Ni Ketut Supasti Dharmawan \\ Fakutas Hukum Universitas Udayana \\ E-mail: arasswk@yahoo.com
}

\begin{abstract}
It is likely not easy to categorize IPR as human right. Based on the human right test and positivism approach, can be categorized into three schemes. : First, IPR is not human rights but it is under purely the dimension of law. Second, some aspects of IPR have potential conflict with human rights. Third, IPR is human rights by emphasizing property rights and individual rights. The relevancy between IPR and the second generation of human rights can be considered based on Article 27.2 UDHR, Article 15 ICESCR and it General Comment No. 17 that emphases the recognition and protection of art and literary works.
\end{abstract}

Key words: human right, IPR, relevancy, second generation

\begin{abstract}
Abstrak
Tidak mudah mengkategorisasikan HKI sebagai HAM.Berdasarkan pengetesan elemen-elemen HAM serta pendekatan positivis terhadap keberadaan HKI, hasil kajian menunjukkan ada tiga sekema: Pertama, HKI bukan dimensi HAM dan sepenuhnya hak yang berkaitan dengan hukum. Kedua, HKI dalam beberapa aspeknya memiliki potensi konflik dengan HAM. Ketiga, HKI adalah HAM dengan penekanan pada property rights dan individual rights. Relevansi antara HKI dengan HAM Generasi Kedua dikuatkan keberadaannya berdasarkan ketentuan Pasal 27.2 UDHR, Pasal 15 ICESCR serta General Comment 17 berupa pengakuan dan perlindungan atas hak yang berkaitan dengan karya intelektual di bidang penulisan karya ilmiah, seni dan sastra.
\end{abstract}

Kata kunci: HAM, HKI, Relevansi, Generasi Kedua.

\section{Pendahuluan}

WTO-TRIPs Agreement adalah perjanjian internasional pertama yang mengatur standar minimum dalam pelindungan Hak Kekayaan Intelektual (HKI). Berkaitan dengan standar minimum tersebut, pengaturan HKI termasuk paten yang semula bersifat national prerogative, kemudian menjadi kewajiban yang harus tunduk pada standar internasional yaitu: "an internationally enforceable institution through rigid treaty and a compulsory and binding dispute resolution procedure" 1 .' Seluruh negara anggota, termasuk Indonesia wajib mentaati standar minimum TRIPs tersebut secara full compliance. Kewajiban tersebut di Indonesia sering dikenal

Jamie Crook, "Balancing Intellectual Property Protection with the Human Right to Health", Berkeley Journal of International Law, Vol. 23, USA: Barkeley Law Univer- dengan sebutan harmonisasi hukum, artinya Indonesia wajib mengharmonisasikan ketentuanketentuan hukum di bidang HKI agar sesuai dengan ketentuan TRIPs Agreement yang telah diratifikasi berdasarkan UU No. 7 Tahun 1994.

Sebagai wujud nyata pentaatan kewajiban harmonisasi hukum di bidang HKI kearah international standard of TRIPs Agreement, Indonesia telah berhasil mengundangkan perlindungan HKI yang berbasis TRIPs Agreement sebagai berikut. Rahasia Dagang diatur dalam UU No. 30 Tahun 2000, Desain Industri berdasarkan UU No. 31 Tahun 2000, Desain Tata Letak Sirkuit Terpadu diatur UU No. 32 Tahun 2000, UU No. 14 Tahun 2001 Tentang Paten, Merek diatur melalui

sity of California, hlm. 530, tersedia di: http://scholarship.law.berkeley.edu/bjil/vol23/iss3/l, diakses pada tanggal 26 April 2014. 
UU No. 15 Tahun 2001, serta Hak Cipta berdasarkan UU No. 19 Tahun 2002. Keseluruhan perundang-undangan tersebut mengatur dan memberikan perlindungan hukum berupa hak eksklusif bagi pemilik maupun pemegang HKI.

Sehubungan dengan perlindungan hukum serta keberadaan hak eksklusif atas karya-karya intelektual, dalam perkembangannya seringkali keberadaan dan perlindungan hak pencipta mau pun hak penemu atas karya-karya intelektualnya dikaitkan dengan Hak Asasi Manusia (HAM), khususnya HAM Generasi Kedua yaitu HAM yang berkaitan dengan ekonomi, sosial dan budaya (HAM Ekosob). Wacana serta diskusi-diskusi tentang apakah HKI adalah bagian dari HAM masih terus diperdebatkan baik dalam forum nasional maupun internasional. Berkaitan dengan hal tersebut tampaknya belum ada suatu jawaban yang pasti, oleh karena itu menjadi penting untuk dikaji tentang apakah HKI merupakan HAM, atau adakah relevansinya antara HKI dengan HAM khususnya HAM Generasi Kedua.

\section{Permasalahan}

Sesuai dengan latar belakang masalah, maka permasalahan yang dibahas dalam tulisan ini adalah sebagai berikut. Pertama, apakah Hak Kekayaan Intelektual itu dapat dikategorisasikan sebagai Hak Asasi Manusia?, kedua, bagaimana relevansi antara HKI dengan HAM Generasi Kedua atau HAM Ekosob?.

\section{Metode Penelitian}

Penulisan karya tulis ini diawali dengan suatu penelitian hukum yang menggunakan metode penelitian hukum normatif, dengan suatu pendekatan: Statute approach, conceptual approach, serta comparative approach. Bahan-bahan hukum yang dikaji dalam tulisan ini terdiri dari bahan hukum primer, yaitu: UU No. 19 Tahun 2002, UU No. 15 Tahun 2001, UU No. 14 Tahun 2001, UU No. 39 Tahun 1999, UU No. 11 Tahun 2005 tentang ratifikasi ICESC, UUD 1945, UDHR 1948, ICCPR, ICESCR, serta bahan hukum sekunder yaitu kajian HKI dan HAM yang tertuang sebagai tulisan ilmiah dalam berbagai kepustakaan. Bahan hukum tersebut di atas diana- isis dan disajikan dengan menggunakan tehnik analisis deskriptif kualitatif.

\section{Pembahasan \\ Kategorisasi HKI sebagai HAM}

Berkaitan dengan fokus kajian apakah HKI dapat dikategorisasikan sebagai HAM atau tidak, maka untuk mendapatkan kejelasan tampaknya dua rezim hukum tersebut harus dikaji satu persatu secara detail baik yang menyangkut konsep dasar maupun filosofi yang melandasi perlindungan hukumnya. Declaration of Human Rights 1948 (UDHR) atau yang di Indonesia dikenal dengan sebutan DUHAM merupakan fundamental pengaturan dan perlindungan HAM sedunia, yang kemudian diikuti oleh berbagai instrumen internasional di bidang HAM. Keberadaan UDHR serta perkembangan HAM internasional, membawa pengaruh yang sangat signifikan terhadap keberadaan serta penegakan hukum bidang HAM di Indonesia. Negara-negara berkembang termasuk di Indonesia masih terus dikritisi oleh dunia internasional sebagai negara yang tingkat pelanggaran HAM-nya masih tinggi. Beberapa contoh kasus pelanggaran HAM: pelanggaran HAM di Bhopal India, Filartiga v. Pena-Irala 1980, Wiwa v. Royal Dutch Petroleum Co. Case 2000, Doel v. Unocol Corp., kasus TRisakti, Freeport Case, serta kasus pelanggaran HAM lainnya. Pembahasan tentang perlindungan dan pelanggaran HAM pada awalnya di tingkat internasional lebih diprioritaskan pada HAM Generasi Pertama yaitu International Covenant on Civil and Political Rights (ICCPR), sedangkan HAM Generasi Kedua yaitu International Covenant on Economic, Social and Cultural Rights (ICESCR) tampak termarginalkan. Dalam perkembangannya, pengakuan terhadap HAM Generasi Kedua mulai menguat, bahkan dalam Konferensi Vienna (the World Human Rights Conference) keseimbangan pengakuan terhadap jenis HAM ini terus disuarakan dengan menyatakan "all human rights are universal, indivisible, interdependent and in- 
terrelated"2. Pengakuan dan pengkajian akan keberadaan HAM ekonomi, sosial dan budaya terus meningkat serta lebih seimbang, termasuk mengkaitkannya dengan Hak Kekayaan Intelektual. $^{3}$

Berbagai usaha telah dilakukan untuk mencegah dan meminimalisasi pelanggaran HAM seperti sosialisasi dan rencana aksi telah banyak dilakukan agar negara-negara di dunia serta masyarakatnya mengetahui, memahami, menghormati, melindungi dan menegakkan ketentuanketentuan hukum yang berkaitan dengan perlindungan HAM. Untuk ikut serta dalam peradaban dunia serta penghormatan dan penegakan HAM sedunia, Indonesia telah ikut dalam berbagai Konvensi atau perjanjian internasional di bidang HAM seperti: Convention Against Torture, CEDOW, ICCPR, serta ICESCR.

Hak Asasi Manusi sangat penting untuk di tegakkan, sehubungan dengan penegakan serta perlindungan hukum tersebut, Indonesia telah mengundangkan UU No. 39 Tahun 1999 Tentang Hak Asasi Manusia, yang pada intinya mengatur HAM sebagai hak dasar yang melekat secara kodrati pada diri manusia. Sebagai anggota Perserikatan Bangsa-Bangsa, Indonesia memiliki tanggung jawab moral dan hukum untuk melaksanakan UDHR 1948 serta berbagai instrumen internasional di bidang HAM yang sudah diratifikasi.

Secara nasional, berdasarkan Pasal 1 Ayat (1) UU No. 39 Tahun 1999 yang mengatur tentang pengertian HAM, dapat diketahui bahwa

2 Patricia Freeney, "Business and Human Rights: The Struggle For Accountability in the UN And The Future Direction of The Advocacy Agenda", SUR International Journal on Human Rights University Network, Vol.6 No. 11, ISSN 1806-6445, 2009, English, Portuguese and Spanish.hlm. 163-164, tersedia di: http: / /www.surjournal.org., diakses tanggal 28 Maret 2014.

3 Hukum Hak Kekayaan Intelektual pada intinya memberikan perlindungan kepada pencipta, penemu dan jenis HKI lainnya dengan memberikan kepada mereka property rights atas karya-karyanya yang berasal dari kreatifitas intelektualnya. Lihat Rahul Dogra, Vijay Dhiman and Nipun Gupta, "Intellectual Property Rights and Mechanism Intellectual Property Protection: A Review", International Journal of Pharmaceutical Sciences and Research, IJPSR, Vol. 3 No. 11, 2012, Singapore, hlm. 4050, tersedia di: http://www.ijpsr.com/v311/index. html, diakses tanggal 17 Juni 2014.

4 Lihat Laurence R. Helfer, "Toward a Human Rights Framework for Intellectual Property", The University of $\mathrm{Ca}$ -
HAM wajib dihormati, dijunjung tinggi dan dilindungi oleh setiap orang termasuk negara demi perlindungan terhadap harkat dan martabat manusia. HAM sebagimana diatur dalam the International Bill of Rights (UDHR 1948, ICCPR, ICES$C R$ ) pada intinya mengakui perlindungan terhadap Hak Ekosob (ekonomi, sosial dan budaya) serta hak-hak sipil dan politik.

Berkaitan dengan justifikasi pengakuan dan perlindungan HKI sebagai bagian dari HAM, para penstudi acapkali mengkaitkannya dengan UDHR 1948, khususnya Article 27.2 UDHR serta ICESCR. ${ }^{4}$ Sesungguhnya kedua instrumen internasional tersebut tidak menyebutkan secara eksplisit tentang istilah Intellectual Property Rights atau dikenal dengan istilah Hak Kekayaan Intelektual di Indonesia, namun Article 27.2 UDHR 1948 menyatakan: "Everyone has the rights to the protection of the moral and material interests resulting from any scientific, literary or artistic production of which he is the author". Kiranya melalui Pasal 27.2 UDHR dapat diketahui ada pengaturan HKI dalam instrumen HAM, khususnya di bidang Hak Cipta karena menyangkut hasil karya ilmiah, kesusastraan maupun kesenian. Dengan mencermati ketentuan Article 27.2 UDHR atau Pasal 27 (2) DUHAM dapat dikemukakan bahwa HKI, khususnya Hak Cipta ${ }^{5}$ memiliki relevansi serta mendapat perlindungan dalam dimensi HAM. Ketentuan Article 27 UDHR 1948 sesungguhnya tidak hanya mengakui dan memberi perlindungan kepada pencipta atas hak-hak yang dimilikinya, namun bersamaan dengan itu

lifornia Davis Law Review, U.C. Davis L. Rev., Vol. 40, 2006-2007, California: The University of California, hlm. 975-976, tersedia di http://www.heinonline.org/HOL/ Print?collection=journals\&handle=hein.journals $/$ davis 40 \&id=979, diakses 17 Juni 2014. Lihat pula Sharon E. Foster "Prelude to Compatibility between Human Rights and Intellectual Property", Chicago Journal of International Law, Chi. J. Int'l L., Vol 9 No. 1 2008-2009, Chicago: The University of Chicago Law School, hlm. 171-172, tersedia di: http://www.heinonline.org/HOL/Print?collection= journals\&handle=hein. journals/cji19\&id=175, diakses 17 Juni 2014.

5 Hak Cipta atau Copyright dalam TRIPs Agreement diatur dalam Article 9-Article14. Di Indonesia, Hak Cipta sebagai salah satu HKI diatur berdasarkan Undang-Undang No. 19 Tahun 2002 Tentang Hak Cipta. Pasal 1 angka 3 mengatur bahwa ciptaan yang dilindungi adalah setiap karya cipta yang menunjukkan keasliannya dalam lapangan ilmu pengetahuan, seni atau sastra. 
melalui Article 27.1 UDHR 1948 juga mengakui adanya hak bagi setiap orang untuk menggunakan dan memanfaatkan karya HKI tersebut.

Pengakuan dan perlindungan terhadap hak-hak yang melekat atas karya-karya individual sebagaimana diatur dalam Article 27. 2 UDHR 1948 sangat dipengaruhi oleh konsep berpikir Mazhab Hukum Alam seperti dikenal pada negara-negara penganut Civil Law System. Berkaitan dengan pengakuan dan perlindungan atas hak milik, Article 2 UDHR 1948 juga mengatur bahwa setiap orang tanpa membedakan ras dan warna kulit, agama, jenis kelamin maupun kebangsaan berhak atas semua hak dan kebebasankebebasan sebagaimana tercantum di dalam UDHR atau di Indonesia dikenal sebagai DUHAM (Deklarasi Universal HAM). Deklarasi ini juga mengatur prihal hak milik atas harta. Harta milik baik yang dimiliki secara sendiri maupun bersama tidak boleh diambil secara semena-mena oleh siapapun juga. Article 17.1.UDHR 1948 menentukan "Everyone has the right to own property alone as well as in association with others". Lebih lanjut Article 17.2 UDHR 1948 menentukan bahwa "No one shall be arbitrarily deprived of his property". Meskipun Article 17 $U D H R$ ini mengatur property secara umum, namun ketentuan tersebut juga dapat dipergunakan sebagai justifikasi pengakuan terhadap hakhak yang berkaitan dengan intellectual property.

Sejalan dengan ketentuan Article 17 UDHR yang memberi perlindungan bagi setiap orang untuk mempertahankan haknya terutama yang berkaitan dengan hak miliknya dari perbuatan semena-mena pihak lain, Hector Mac Queen menekankan bahwa setiap orang yang berhasil mewujudkan karya-karya kreatif dari kemampuan intelektualnya, maka berhak mendapat perlindungan hukum. 6 " $A$ property paradigm implies $a$ system of control to be exercised by the right holder, that is, control of the subject matter of his property rights. No one can take, use or otherwise interfere with the property without permission from the right holder."
Keberadaan perlindungan HKI dalam konteks HAM selain dapat diketahui dalam UDHR 1948, juga implisit dalam berbagai instrumen internasional HAM di antaranya dalam ICESCR 1966, yang sudah diratifikasi oleh Indonesia melalui Undang-Undang No. 11 Tahun 2005 Dalam ketentuan Article 15.1 (c) of the ICESCR ditentukan "The State Parties to the present Covenant recognize the right of everyone to benefit from the protection of the moral and material interests resulting from anyscientific, literary or artistic productions of which he is the author". Meskipun tidak menyebutnya secara eksplisit tentang Hak Kekayaan Intelektual, namun secara tegas Kovenan Internasional ini mengakui dengan mengatur bahwa negara-negara yang menandatangani Kovenan ini mengakui perlindungan kepentingan moral dan material atas karya yang diciptakan oleh seseorang di bidang karya ilmiah, sastra atau seni. Dalam konteks ini, kiranya dapat dikemukakan bahwa perlindungan Hak kekayaan Intelektual dalam bentuk karya ilmiah, sastra dan ilmu pengetahuan yang berhasil diciptakan oleh pencipta dilindungi sebagai Hak Cipta secara internasional dalam TRIPS Agreement dan Berne Convention, serta secara nasional di Indonesia dalam Undang-Undang Hak Cipta.

Pengakuan negara dalam konteks HAM terhadap hasil karya intelektual juga dapat dicermati dari ketentuan Article 15.2, Article 15.3 serta Article 15.4 ICESCR. Secara lebih detail ketentuan tersebut mengatur tentang usaha-usaha yang harus dilakukan oleh negara anggota seperti melestarikan, mengembangkan, serta menyebarkan hasil ilmu pengetahuan yang lahir dari hasil karya dan karsa intelektual manusia, guna mewujudkan perlindungan hak sebagaimana diatur dalam Article 15.1 ICESCR.

Pengakuan akan keberadaan hak yang berkaitan dengan kekayaan intelektual tercermin dalam Article 14 African Charter on Human and Peoples' Rights (ACHPR), meskipun pengakuan tersebut lebih dikaitkan dengan kepentingan masyarakat dalam menggunakan karya-karya in-

6 Hector Mac Queen, Charlotte Waelde \& Graeme Laurie, 2008, Contemporary Intellectual Property Law and Policy, New York, Oxford University Press., hlm. 7. 
telektual. ${ }^{7}$ Keterkaitan antara Hak Asasi Manusia dengan pengakuan dan perlindungan Hak Kekayaan Intelektual juga dapat dicermati keberadaannya pada Article 21.1. of American Convention on Human Rights (1969), yang secara eksplisit menentukan sebagai Right to property. Selengkapnya Article 21 Right to Property of American Convention on Human Rights (1969):

1. Everyone has the right to the use and enjoyment of his property. The law may subordinate such use and enjoyment to the interest of society.

2. No one shall be deprived of his property except upon payment of just compensation, for reasons of public utility or social interest, and in the cases and according to the forms established by law.

Sementara itu dalam European Convention on Human Rights, khususnya melalui Article 1 of First Protocol (1952) mengatur tentang pengakuan terhadap protection of property, yang menentukan: "Every natural or legal person is entitled to the peaceful enjoyment of his possessions. No one shall be deprived of his possessions expept in the public interet and subject to the conditions provided for by law and by the general principles of international law".

Keterkaitan antara perlindungan dan pengakuan hak atas karya intelektual manusia dengan hak asasi manusia meskipun secara implisit tercermin dalam berbagai instrumen internasional, namun tidak mudah untuk menyebutkan bahwa HKI bagian dari HAM. Berbagai kendala muncul ketika dilakukan pengetesan terhadap apakah HKI itu HAM, jika HAM apakah dapat dikategorisasikan sebagai HAM fundamental seperti halnya hak untuk hidup?. Pertanyaan-pertanyaan seperti itu mengemuka, dan perlu dilakukan pengkajian yang lebih mendalam untuk dapat memberi jawabannya.

Ketidakjelasan tentang apakah HKI itu memang sejatinya HAM, sama rumitnya dengan pengkajian munculnya rezim-rezim baru di bi-

Pakar yang menekuni kaitan antara HAM dan HKI memandang bahwa "Interest of public need or in the general interest of the community" dalam kaitannya dengan penggunaan karya-karya HKI menjadi salah satu substansi dalam pengaturan Article 14 of ACHPR. dang HAM, seperti contoh HAM Generasi Ketiga yaitu: the right to clean environment, the right to peace, dan the right to development, yang eksis dengan ketidakpastian. All human rights of the third generation are surrounded by grave uncertainties regarding their holders, the dutybearers, and their substance. ${ }^{8}$ Sederetan HAMHAM baru telah muncul ke permukaan, mulai dari yang tergolong dalam HAM Generasi Ketiga, kemudian the right to health care, hingga the right to property dan bahkan lebih jauh the right to intellectual property. Ada elemen-elemen mendasar yang harus dipenuhi agar suatu rezim baru dapat dikatagorikan sebagai "Human Right". Adapun elemen-elemen yang digunakan untuk mengetes berkaitan dengan: The Holders (siapa pemegang haknya); The Duty-Bearers (siapa yang berkewajiban untuk mewujudkan); dan The Substance ( apa yang menjadi substansi dari jenis HAM tersebut). ${ }^{9}$

Memang tidak - mudah dalam konteks pengetesan elemen-elemen tersebut di atas - untuk menyatakan dengan serta merta bahwa hak kekayaan intelektual adalah HAM. Elemen pertama, tentang The Holders (siapa pemegang haknya) barangkali dapat terpenuhi, karena sudah pasti pemegang haknya adalah si pemilik karya intelektual itu sendiri bisa pencipta, penemu, ataupun pendesain. Elemen kedua, yaitu tentang The Duty-Bearers (siapa yang berkewajiban untuk mewujudkan), juga dapat dinyatakan memenuhi syarat, dalam konteks ini negara yang berkewajiban untuk mewujudkan perlindungan, dalam konteks HAM Ekosob, yaitu HAM generasi Kedua, intervensi negara terbuka lebar dalam pencarian dan pemenuhan terhadap martabat manusia dalam konteks tuntutan persamaan ekonomi, sosial dan budaya. Pengetesan terhadap elemen yang ketiga hasilnya mungkin tidak memuaskan seperti halnya pengetesan terhadap elemen pertama dan elemen kedua. Elemen Ketiga, tentang The Substance (apa yang menjadi substansi dari jenis HAM tersebut) tidak mudah

8 Christian Tomuschat, 2008, Human Rights between Idealism and Realsm, New York: Oxford University Press, hlm. 57.

9 Ibid, hlm. 58-59 
untuk dipenuhi serta penuh dengan ketidakjelasan.

Sebagaimana diketahui bahwa substansi HAM adalah hak yang fundamental yang ada pada setiap manusia (everyone HAM bersifat universal dan egalitarian. Keberadaan hak-hak tersebut eksis sebagai hak alami (natural rights) yang melekat secara alami pada manusia sepanjang hayatnya ataupun ha-hak yang diatur dalam suatu sistem hukum secara formal (legal rights) baik dalam hukum nasional maupun hukum internasional. Sementara itu, jika dikaitkan dengan keberadaan Hak Kekayaan Intelektual, kemelekatan hak pada pencipta atau penemu atas karya-karya intelektualnya dibatasi oleh jangka waktu, seperti misalnya jangka waktu perlindungan untuk Paten selama 20 tahun. Dalam konteks ini, hasil test menunjukkan tidak mudah untuk menyatakan begitu saja bahwa hak atas kekayaan intelektual adalah hak asasi manusia, karena salah satu unsur atau elemen pengetesannya tidak dapat dipenuhi secara sempurna.

Berdasarkan hasil tes elemen-elemen HAM sebagaimana tersebut di atas tampak HKI tidak memenuhi seluruh unsur elemen HAM, sehingga tidak mudah begitu saja menyatakan bahwa HKI juga adalah HAM. Keraguan lainnya mengemuka ditengah-tengah usaha dan kampanye mempromosikan HAM untuk kesehatan maupun pendidikan untuk publik terutama untuk kalangan grassroots agar dapat mengenyam hidup secara lebih sehat dan baik melalui berbagai advokasi, kebijakan, serta berbagai peraturan hukum, namun pada saat bersamaan secara paradok para pengusaha obat farmasi yang memiliki kepentingan terhadap penemuan obat-obatan mengklaim bahwa mereka juga memiliki HAM atas temuan

10 Yousuf A Vawda, "Achieving social justice in the human rights/intellectual property debate: Realizing the goal of access to medicines", African Human Rights Law Journal, Vol. 13, No. 1, 2013, Africa, hlm. 57, Africa, tersedia di http://www.ahrlj.up.ac.za/issues/2013/volume-13no-1-2013, diakses 27 April 2014.

11 Duncan Matthews, "When Framing Meets Law: Using Human Rights as a Practical Instrument to Facilitate Access to Medicines in Developing Countries", The WIPO Journal Analysis of Intellectual Property Issues (W.I.P. O.J.00) Sweet \& Maxwell, Vol. 3, Issue 1, 2011, the UK., hlm. 127

12 Mirela V. Hristova, "Are Intellectual Property Rights Human Rights?, Patent Protection and the Right to obat-obatannya dalam bentuk hak eksklusif paten. ${ }^{10}$

Pendekatan yang berbasis HAM digunakan pertama kali oleh LSM (NGOs International), mereka dengan bahasa emotive (mengharukan) mengkampanyekan bahwa kesehatan masyarakat, akses terhadap obat-obatan, hak atas kesehatan masyarakat, serta hak hidup menjadi berisiko dengan ketentuan paten dalam TRIPs Agreement. ${ }^{11}$ Dalam situasi seperti itu tentu tidak mudah untuk menentukan keberpihakan HAM pada kepentingan individu (individual right) sebagaimana terkonstruksi dalam TRIPs Agreement yang syarat dengan perlindungan terhadap kepentingan material, ketimbang kepentingan masyarakat bawah (Communal rights) untuk mendapatkan akses obat-obatan, terutama ketika masyarakat kelas bawah berhadapan dengan persoalan kesehatan dan penyakit yang mematikan seperti terjangkit HIV / AIDS yang terjadi pada masyarakat Afrika Selatan. Berkaitan dengan hak atas kesehatan, menurut Aristoteles setiap manusia memiliki hak mutlak untuk mendapatkan kesehatan yang baik sebagai bagian dari masyarakat. ${ }^{12} \mathrm{Di}$ sisi lain, para studi yang pro dengan reward theory serta menghargai hasil karya kreatif yang bersumber dari intelektual manusia secara individu mengaganggap bahwa hak atas karya tersebut sangat penting mendapat perlindungan. TRIPs Agreement bahkan memperkuat perlindungan HKI secara internasional serta bertujuan meningkatkan kewajiban negara-negara anggota di level nasional dalam pentaatan terhadap standar TRIPs, serta membatasi dibuatnya kebijakan-kebijakan di level nasional terkait dengan perlindungan HKI termasuk didalamnya perlindungan terhadap farmasi. ${ }^{13}$ Pengkategorisasian-

Health", Journal of the Patent \& Trademark Office Society, J.Pat.\& Trademark Off. Soc"y, Vol. 93, No. 3, 339, 2011, UK, Cardiff University. hlm. 355, tersedia di: http: / / www. heinonline.org/HOL/Page?page=339\&handl $\mathrm{e}=$ hein.journals\%2Fjpatos93\&collection=journals\#345, diakses tanggal 17 Juni 2014.

13 Amanda Barratt, "The Curious Absence of Human Rights: Can the WIPO Development Agenda Transform Intellectual Property Negotiation?, "Law, Democracy \& Development Law Journal, Vol. 14, 2010, Southern African. hlm. 17-18, tersedia di: http://www.ajol.info/index.php/ ldd/issue/view/8292, diakses 28 April 2014. 
nya suatu regim tertentu sebagai HAM atau tidak kiranya relevan menggunakan pendekatan positivis. Sebagai titik awal ditelusuri dan dikaji dari berbagai instrumen hukum yang mengatur HAM, seperti misalnya apakah UDHR, ICCPR, maupun ICESCR mengatur regim tertentu seperti hak buruh (labour right) tersebut di dalamnya. ${ }^{14}$ Dengan demikian dalam kerangka pendekatan positivisl pertanyaannya adalah apakah instrumeninstrumen HAM mengatur HKI, jika ya maka HKI dapat dikategorisasikan sebagai HAM.

Sehubungan dengan pemahaman dan perdebatan seperti tersebut di atas, Duncan Matthews mengemukakan ada tiga kemungkinan interpretasi yang dapat dikemukakan untuk menganalisis relevansi antara HKI dan HAM. Pertama, HKI bukan dimensi HAM dan sepenuhnya hak yang berkaitan dengan hukum; kedua, HKI adalah HAM dengan penekanan pada property rights dan individual rights; dan ketiga, beberapa aspek dari HKI memiliki potensial implikasi yang berlawanan dengan HAM. ${ }^{15}$

\section{HKI dalam Kerangka HAM Generasi Kedua (EKOSOB)}

TRIPs Agreement, ${ }^{16}$ yaitu salah satu perjanjian internasional yang sekarang ini mengatur perlindungan untuk seluruh jenis Hak Kekayaan Intelektual (HKI) seringkali dikritisi dan dianggap konflik dengan HAM yang berkaitan dengan the right to education karena TRIPs dalam kolaborasinya dengan Konvensi Berne tampaknya lebih memberi proteksi berkaitan dengan material interests kepada para authors yang telah menghasilkan karya-karya literary and artistic works, ketimbang mengedepankan persyaratan HAM untuk primary education for free. Perlindungan yang diberikan oleh TRIPs sesungguhnya relevan dengan HAM khususnya HAM bagi pengarang atau

14 Virginia Mantouvalou, "Are Labour Rights Human Rights?", European Labour Law Journal, Vol. 3, No. 2, 2012, New York, hlm. 152.

15 Duncan Matthews, "Intellectual Property, Human Rights and the Right to Health", Legal Studies Research, Paper No. 24, 2009, the UK., Queen Mary University of London., hlm. 2. tersedia di: http://ssrn.com/abstract=1414900, diakses tanggal 27 April 2014.

16 Berkaitan dengan perlindungan HKI, Berdasarkan Article 1 TRIPs Agreement mempersyaratkan bahwa seluruh negara anggota diwajibkan untuk mematuhi standar TRIPs pencipta. Meski dalam Konvensi-Konvensi HAM tidak secara spesifik mengakui perlindungan terhadap Hak Kekayaan Intelektual (HKI), namun Sharon E. Foster mengemukakan bahwa the language of Article 27 (2) is very clear granting author's moral and material interests the status of human rights. Lebih lanjut penguatan tentang pengakuan HKI sebagai HAM juga dapat dicermati dari Paragraph 15(1)(c) ICESCR. Sehubungan dengan ketentuan tersebut, the Committee on Economic Social and Cultural Rights (the 'Committee') telah mengeluarkan General Comment No. 17 yang menginterpretasikan adanya perlindungan HAM baik moral maupun material interests bagi authors. ${ }^{17}$

Perlindungan hukum, yaitu berupa pemberian reward atas material interests kepada author menjadi relevan dan adil karena dalam menghasilkan karya yang berkaitan dengan HKI mereka telah mengorbankan banyak waktu, tenaga, pemikiran serta biaya dalam menghasilkan kreatifitas intelektual yang menunjukkan keaslian atau orisinalitas (the expenditure of independent effort, skill and labour by the author is often seen as the essence of originality in the field of copyright). ${ }^{18}$ Untuk mampu menghasilkan karya cipta yang asli atau orisinal tidaklah mudah, para pencipta telah mengorbankan banyak hal untuk itu, oleh karenanya sangat pantas dilindungi haknya atas suatu karya intelektual. Berkaitan dengan persyaratan originality dalam karya cipta, David Bainbridge mengemukakan bahwa the work is the result of skill, judgment and labour and to have originated from the author in the sense that it has not been copied from another work.

Berdasar pada perlindungan dan keberadaan hak author dalam UDHR maupun konvensi HAM Generasi Kedua yaitu ICESCR maupun Gene-

serta memberikan kebebasan kepada negara anggota untuk menentukan metode yang sesuai untuk melaksanakan ketentuan TRIPs sesuai dengan sistem hukum negara anggota masing-masing.

17 Sharon E.Foster, 2008, The Conflict between the Human Right to Education and Copyright, in Paul L.C. Torremans (ed), Intellectual Property and Human Rights Enhanced Edition of Copyright and Human Rights, The Netherlands,: Kluwer Law International, hlm. 287- 299.

18 Hector Mac Queen, Charlotte Waelde \& Graeme Laurie, op.cit, hlm. 52. 
ral Comment 17-nya, maka sudah seyogyanya negara peserta termasuk Indonesia mengimplementasikan pengakuan dan perlindungan author yang pada intinya perlindungan terhadap karyakarya HKI yang dihasilkan oleh author atau di Indonesia dikenal sebagai pencipta dalam tataran praktik, salah satunya menuangkannya dalam RANHAM.

RANHAM dapat menjadi alat diplomasi Indonesia di dunia internasional, sebagai salah satu bentuk kesungguhan dan komitmen Indonesia dalam memenuhi dan melindungi HAM. Sekarang ini masih sering ada sorotan pada Indonesia berkaitan dengan pelanggaran HAM. Berkaitan dengan pengakuan dan perlindungan terhadap karya-karya intelektual baik dalam bentuk seni, sastra dan ilmu pengetahuan sebagaimana ditegaskan dalam Article 15.1. (c) ICESCR, dapat dikemukakan bahwa Hak Cipta sebagai satu satu jenis dari Hak Kekayaan Intelektual tercakup, dan bahkan mungkin dapat disebutkan sebagai implementasi dari Hak Asasi Manusia Generasi Kedua (HAM EKOSOB). Bahkan dengan mengkaitkannya dengan Article 15.2, Article 15.3 serta Article 15.4 ICESCR, yang pada intinya mengatur tentang usaha negara dalam melindungi dan mengakui hak pencipta atas karya karya HKI di bidang Hak Cipta serta pemanfaatannya bagi masyarakat, maka sudah sepatutnya hal-hal tersebut tertuang dalam RANHAM.

RANHAM yang berkaitan dengan pengakuan dan perlindungan Hak Cipta tidak akan dapat disusun dengan baik tanpa memahami sistem perlindungan Hak Cipta itu sendiri, oleh karenanya pengkajian terhadap UU No. 19 Tahun 2001 tentang Hak Cipta menjadi sangat penting dan relevan sebagai salah satu agenda aktifitas dalam penyusunan RENHAM. Undang-undang Hak Cipta mengatur perlindungan terhadap hasil karya pencipta di bidang ilmu pengetahuan, seni dan sastra. Karya-karya tersebut baru mendapat perlindungan hukum apabila telah diwujudkan sebagai ciptaan, yaitu karya nyata yang berwu-

19 Salah satu kasus berkaitan dengan ide dan ekspresi untuk lahirnya Hak Cipta adalah kasus Sauthco, Inc. v. Kanebridge Corp., Lihat Jeffrey Malkan, "Rule-Based Expression in Copyright Law", Buffalo Law Review, Buff.L.Rev.433, Vol. 57 Issue 2, New York: University of Buffalo, hlm. jud (expression work). Hukum hak cipta tidak melindungi ciptaan yang masih berupa ide (idea) semata. ${ }^{19}$ TRIPs Agreement Article 9 (2) menegaskan bahwa Hak Cipta melindungi karya nyata (expression work). According to TRIPs that "copyrights protection shall extend to expressions and not to ideas, procedures, and methods of operation or mathematical concepts as such".

Di Indonesia secara nasional Hak Cipta diatur dalam UU No. 19 Tahun 2002 tentang Hak Cipta, sementara itu secara Internasional pengaturan Hak Cipta dapat diketahui melalui berbagai Konvensi seperti: Berne Convention, UCC (Universal Copyright Conventioan), serta TRIPs Agreement. Menurut Miller dan Davis, pemberian hak cipta didasarkan pada kriteria keaslian (originality). Hasil ciptaan secara asli adalah buah pemikiran kreatif dari pencipta bukan merupakan hasil peniruan dari karya pihak lain. Dalam Pasal 1 angka 3 UU No. 19 tahun 2002 diatur prihal keaslian karya cipta. untuk mendapat perlindungan hukum hak cipta, hal yang penting adalah hasil karya cipta yang khas dan bersifat pribadi serta menunjukkan unsur keaslian.

Secara lebih rinci karya intelektual manusia yang mendapat perlindungan Hak Cipta diatur berdasarkan ketentuan Pasal 12 UU No. 19 tahun 2002 dari huruf a yang berkaitan dengan karya ilmiah dan penulisan hingga huruf I yang berkaitan dengan terjemahan, data base, hingga karya pengalihwujudan. Pencipta yang telah melahirkan karya cipta akan memiliki hak khusus atau hak eksklusif atas karya ciptaannya, yang perlindungannya timbul secara otomatis setelah suatu ciptaan dilahirkan (Pasal 2 ayat 1). Perlindungan hukum terhadap hasil karya cipta diperoleh oleh pencipta secara otomatis, artinya tanpa melalui proses pendaftaran terlebih dhulu pencipta secara otomatis sudah mendapat perlindungan hukum atas karya ciptanya begitu karya tersebut sudah diwujudkan dalam bentuk karya cipta nyata (expression work). Hal ini dimungkinkan, karena dalam hukum hak cipta di-

435, tersedia di http://www. heinonline.org/HOL/Print? collection=journals\&handle=hein. journals $/$ buflr57\&id $=4$ 37, diakses tanggal 17 Juni 2014 
anut sistem perlindungan secara otomatis (automatically protection).

Konsep perlindungan otomatis dilandasi oleh Konvensi Berne. Salah satu prinsip dari Konvensi Burne (Berne Convention) adalah Automaticelly Protection. Menurut konsep perlindungan ini, Hak Cipta boleh didaftar boleh juga tidak. Pendaftaran suatu ciptaan tidak merupakan suatu kewajiban berdasarkan Pasal 35 Ayat (4) U.U. Hak Cipta. Dengan demikian, berdasarkan ketentuan tersebut pendaftaran Hak Cipta bersifat tidak mutlak. Pendaftaran ciptaan bersifat " $\mathrm{Fa}$ kultatif". Hal tersebut berbeda dengan kelompok HKI lainnya, seperti misalnya Paten dan Merek yang mempersyaratkan proses pendaftaran agar mendapat perlindungan hukum Meskipun menurut hukum Hak Cipta perlindungan hak cipta bersifat otomtis yang diperoleh oleh pencipta sejak ciptaan lahir, dan tidak harus melalui proses pendaftaran, namun kalau dilakukan pendaftaran itu akan lebih baik dan lebih menguntungkan, karena dengan pendaftaran hak, setidaknya akan ada bukti formal sebagai anggapan adanya hak cipta jika tidak terbukti sebaliknya. Dengan adanya proses pendaftaran jika terjadi peniruan atau penjiplakan karya cipta, si pencipta lebih mudah membuktikan dan mengajukan tuntutan, karena ada bukti formal pendaftaran.

Guna lebih memberi jaminan kepastian hukum dan menguatkan adanya perlindungan hukum atas karya Cipta, si Pencipta atau Pemegang Hak Cipta umumnya akan membubuhkan tanda ( ) dalam karya ciptanya sebagai bukti bahwa karya tersebut memperoleh perlindungan Hak Cipta. Pencipta memiliki hak eksklusif, yaitu yaitu serangkaian hak dalam bentuk: reproduction right, adaptation right, distribution right, public performing right, serta broadcasting right atas karya ciptanya. Selain berhak menggunakan sendiri, pihak pencipta juga berhak untuk melarang atau mengizinkan pihak lain untuk memanfaatkan karya ciptanya dengan seizin dari pencipta, misalnya melalui mekanisme perjanjian Lisensi.

\section{Penutup}

Simpulan
Berdasarkan pembahasan di atas, dapat ditarik beberapa simpulan. Pertama, pengkategorisasian Hak Kekayaan Intelektual (HKI) sebagai Hak Asasi Manusia (HAM) sampai sekarang masih diperdebatkan. Berbagai pendekatan dipergunakan untuk memahami kategorisasi tersebut seperti elemen pengetesan HAM maupun pendekatan positivis. Tidak mudah mengkategorisaikan HKI sebagai HAM karena salah satu elemen pengetesan HAM (the Holders, the DutyBearrers, the Substance) tidak terpenuhi oleh regim HKI. Setidaknya ada tiga kemungkinan interpretasi yang dapat dikemukakan untuk menganalisis relevansi antara HKI dan HAM. HKI bukan dimensi HAM dan sepenuhnya hak yang berkaitan dengan hukum, HKI adalah HAM dengan penekanan pada property rights dan individual rights, serta beberapa aspek dari HKI memiliki potensial implikasi yang berlawanan dengan HAM.

Kedua, relevansi antara HKI dengan HAM Generasi Kedua dikuatkan berdasarkan Article 27.2 UDHR, Article 15 ICESCR, serta General Comment No. 17 yang menekankan pengakuan dan perlindungan atas hak yang berkaitan dengan karya intelektual di bidang penulisan karya ilmiah, seni.

\section{Saran}

Ada bBeberapa saran yang bisa diberikan dengan mendasarkan pada pemecahan masalah di atas. Pertama, dengan pemahaman HKI adalah bagian dari HAM, maka sudah sewajarnya Pemerintah, termasuk Pemerintah Daerah Provinsi Bali dapat mengagendakan penegakan hukum HKI dalam RANHAM, khususnya HAM Generasi Kedua (HAM Ekosob). Kedua, berkaitan dengan dimasukkannya HKI dalam agenda RANHAM, diharapkan Pemerintah Daerah secara terus menerus mensosialisasikan substansi perlindungan HKI dan relevansinya dengan perlindungan HAM.

\section{DAFTAR PUSTAKA}

Barratt, Amanda. "The Curious Absence of Human Rights: Can the WIPO Development Agenda Transform Intellectual Property Negotiation?". Law, Democracy \& Deve- 
lopment Law Journal. Vol. 14. 2010. Southern African;

Crook. Jamie, "Balancing Intellectual Property Protection with the Human Right to Health". Berkeley Journal of International Law. Vol. 23. 2005. USA: Berkeley Law University of California;

Dogra, Rahul. Vijay Dhiman and Nipun Gupta. "Intellectual Property Rights and Mechanism Intellectual Property Protection: A Review". International Journal of Pharmaceutical Sciences and Research. Vol. 3 No. 11 2012. Singapore;

Foster, Sharon E. 2008. The Conflict between the Human Right to Education and Copyright, in Paul L.C. Torremans (ed). Intellectual Property and Human Rights Enhanced Edition of Copyright and Human Righ$t s$, The Netherlands, Kluwer Law International;

Foster, Sharon E. "Prelude to Compatibility between Human Rights and Intellectual Property", Chicago Journal of International Law. Vol. 9. No. 1. 2008-2009, Chicago: The University of Chicago Law School;

Freeney, Patricia. "Business And Human Rights: The Struggle For Accountability in the UN And The Future Direction of The Advocacy Agenda". SUR International Journal on Human Rights University Network. Vol. 6 No. 11. 2009. English, Portuguese and Spanish;

Helfer, Laurence R. "Toward a Human Rights Framework for Intellectual Property". The University of California Davis Law Review. Vol. 40, 2006-2007. California: The University of California;

Hristova, Mirela V. "Are Intellectual Property Rights Human Rights?, Patent Protection and the Right to Health". Journal of the Patent \& Trademark Office Society. Vol. 93 No. 3. 2011., UK: Cardiff University;

Mac Queen, Hector. Charlotte Waelde \& Graeme Laurie. 2008. Contemporary Intellectual Property Law and Policy. New York: Oxford University Press:

Malkan. Jeffrey, "Rule-Based Expression in Copyright Law". Buffalo Law Review. Vol. 57 Issue 2. 2009. New York: University of Buffalo;

Mantouvalou, Virginia. "Are Labour Rights Human Rights?". European Labour Law Journal. Vol. 3. No. 2. 2012. New York;
Matthews, Duncan. "Intellectual Property, Human Rights and the Right to Health". Legal Studies Research, Paper No. 24, 2009, the UK: Queen Mary University of London;

-.-.-.-. "When Framing Meets Law: Using Human Rights as a Practical Instrument to Facilitate Access to Medicines in Developing Countries". The WIPO Journal Analysis of Intellectual Property Issues (W.I.P.O.J.00) Sweet \& Maxwell. Vol. 3. Issue 1. 2011. the UK;

Tomuschat, Christian. 2008 Human Rights between Idealism and Realism. New York: Oxford University Press;

Vawda, Yousuf A. "Achieving Social Justice in the Human Rights/Intellectual Property Debate: Realizing the goal of access to medicines". African Human Rights Law Journal. Vol. 13. No. 1. 2013. Africa. 